Javier Muñoz-Basols

\title{
Cromatismo y percepción sensorial: nuevos indicios sobre la técnica compositiva de la novela Aura de Carlos Fuentes'
}

\begin{abstract}
Palabras clave: cromatismo, descripción, estilística, hipotiposis, literatura gótica, literatura mexicana, percepción sensorial
\end{abstract}

Pierre Fontanier, en su estudio decimonónico sobre las figuras del discurso, puntualizaba que la hipotiposis: "peint les choses d'une manière si vive et si énergique, qu'elle les met en quelque sorte sous les yeux, et fait d'un récit ou d'une description, une image, un tableau, ou même une scène vivante» [pinta las cosas de una manera tan viva y enérgica que las pone en cierto modo ante nuestros ojos y convierte un relato o una descripción en una imagen, un retrato o incluso una escena viva] (Fontanier, [1827] 1968, 390). En la misma línea de significado, Paul de Man, haciendo referencia a la elaboración discursiva de Kant, nos ofrecía otra definición de dicha figura retórica: «Hypotyposis makes present to the senses something which is not within their reach, not just because it does not happen to be there but because it consists, in whole or in part, of elements too abstract for sensory representation» [La hipotiposis hace presente para los sentidos algo que no está a su alcance, no sólo porque no se encuentra allí mismo, sino porque consiste, ya sea en su totalidad o en parte, en elementos demasiado abstractos para la representación sensorial] (De Man, $1978,26)$.

De entre las principales figuras retóricas del ámbito de la descripción, tales como la écfrasis (representación verbal de una obra de arte), la cronografía (descripción de circunstancias de tiempo), la topografía (descripción de lugares), la prosopografía (descripción del aspecto físico), o la etopeya (descripción del carácter y las costumbres de una persona), es precisamente la hipotiposis, "o descripción de una persona o de un objeto, hecha con gran riqueza plástica de anotaciones y matices sensoriales de forma que pueda producir al lector o receptor la sensación de presencia o evidencia de dicho objeto» (Estébanez Calderón, 2001, 508), el mecanismo retórico por excelencia que en la novela Aura contribuye a conseguir uno de los requisitos principales del género gótico: la pérdida del sentido de la realidad; una constante incertidumbre que

1 Una primera versión de este estudio fue presentada durante el Coloquio Gótico que tuvo lugar en la Facultad de Filosofía y Letras de la Universidad Autónoma de México (UNAM) en abril del 2008. 
en numerosas ocasiones desemboca en el miedo, o incluso el terror, y que se logra apelando a los sentidos ${ }^{2}$.

Por esta razón, lo gótico es a priori una manifestación estética que se nutre de lo sensorial, lo cual Carlos Fuentes justifica en su artículo »On Reading and Writing Myself: How I Wrote Aura «, y cuyo cúmulo de sensaciones en Aura, una de sus mejores creaciones según el propio autor, es el resultado directo de las vivencias personales que impregnan la novela: lugares concretos (Ciudad de México, París), referencias literarias (escritores como Francisco de Quevedo y Villegas, Ueda Akinari, Charles Dickens, Edgar Alan Poe o Henry James), e incluso cinematográficas (la filmografía de Luis Buñuel), o piezas musicales (La Traviata, cantada por María Callas, a la que conoció en persona). Como señala Bell:

It seems unlikely that anything in Carlos Fuentes could be unconscious. $\mathrm{He}$ is the most ostentatiously allusive of writers and his sense of inner or psychic dimension of history leads him to embody it in its successive literary manifestations. Hence his fiction constantly digests previous literature as part of its own historical consciousness. [Parece poco probable que algo en la obra de Carlos Fuentes se articule de manera inconsciente. Es uno de los escritores más ostentosamente alusivos y su sentido de la dimensión psíquica o interna de la historia le lleva a incorporar este aspecto en sus manifestaciones literarias posteriores. De ahí que su ficción constantemente digiera literatura anterior como parte de su propia conciencia histórica] (Bell, 1997, 106).

Sin embargo, y pese a tratarse de una obra sumamente interesante desde el punto de vista estilístico, la crítica no se ha ocupado de profundizar en un análisis que contribuya a desvelar su técnica compositiva. Ya sea por su brevedad, o por su temática gótica -la cual posiblemente no abriría el apetito de numerosos lectores en la época de su publicación- algunos críticos achacan la falta de interés inicial por la novela a que ésta vio la luz en 1962, el mismo año que La muerte de Artemio Cruz (Saludes, 1988).

Paradójicamente, y pese al poco interés que suscitó Aura tras su aparición, cabe mencionar aquí un hecho que irrumpió en el año 2001, que ha acompañado a la obra desde entonces y que, en efecto, corrobora la fuerza ilocutiva de su entramado compositivo casi cuarenta años después de su publicación:

2 En el artículo, »La recreación del género gótico a través de la percepción sensorial: la construcción de la hipotiposis en Aura de Carlos Fuentes«, Atenea 23(2), 2003, pp. 73-85, Javier Muñoz-Basols lleva a cabo una primera aproximación sobre el papel que desempeña la percepción sensorial en la novela, demostrando cómo la hipotiposis es el principal mecanismo retórico que permite establecer un vínculo de unión entre el género gótico y el tipo de descripción que se desarrolla en la trama. Sobre la hipotiposis en otras obras literarias, se pueden consultar los estudios de Carlos Navarro, "La hipotiposis del miedo en El Señor Presidente«, Revista Iberoamericana 32, 1966, pp. 51-61, y de Javier Muñoz-Basols, »Topografía e hipotiposis: dos tipos de 'rebeldía descriptiva' con un propósito conjunto en Nada de Carmen Laforet«, Neophilologus 89(2), 2005, pp. 235-248. 
Georgina Rábago [estudiante de literatura dramática y teatro en la UNAM, en filosofía y letras] narra que como parte de su clase para tercero de secundaria en el Instituto Félix de Jesús Rougier, dejó a sus alumnas leer cuatro de los Doce cuentos peregrinos, de Gabriel García Márquez, y Aura, de Carlos Fuentes. El primer atrevimiento le costó un llamado de atención, el segundo la rescisión de su contrato como maestra de literatura. El padre de familia impulsor de la medida, para quien al parecer Aura representa uno de los papeles que la mujer no debe desempeñar, [era el] secretario de Trabajo, Carlos Abascal, también autor de uno de los discursos más polémicos sobre el papel de la mujer en la sociedad (Ravelo, La jornada, 16 de abril de 2001).

Y parece que más que por el contenido, la suscitada polémica vino provocada en casi su totalidad por el efecto de los matices descriptivos magistralmente desarrollados por el autor, y cuya consecuencia más directa es que el hecho descriptivo se adueña completamente de la narración para inmiscuir al lector en la resolución de sus sentidos:

El párrafo de la novela Aura, de Carlos Fuentes, que desató la indignación del secretario de Trabajo, Carlos Abascal, al grado de subrayarlo y transcribirlo en su carta como prueba de la 'falta' de la maestra Luz María Georgina Rábago Pérez $[. .$.$] no fue lo más atractivo de la lectura que hicieron, de acuerdo con$ la apreciación de la propia maestra de literatura.

- ¿Les pudo atraer a ellas la carga erótica sugerida en el libro?

-Claro que no, porque su primer comentario fue 'Aura y la viejita eran la misma.' No hubo ninguna alusión respecto del sexo. Lo que les llamó la atención era cómo se describía cada cosa, el ambiente que se creaba. Les gustaba, porque se metían en un ambiente incluso de suspenso (Ravelo, $L a$ jornada, 16 de abril de 2001) $)^{3}$

Queda patente, por lo tanto, que en la novela existe un ir más allá que persigue sobrepasar los límites sensoriales y donde el lector no solamente es guiado, sino que se deja guiar seducido por la peculiar técnica compositiva de la novela por lo que, a continuación, analizaremos algunos rasgos estilísticos en los que se da primacía al cromatismo y a la percepción sensorial. Dicho análisis nos permitirá corroborar la relevancia hermenéutica del hecho descriptivo con el que, como veremos, se refuerza el significado global de la obra y en donde lo sensorial y los matices cromáticos no sólo sustentan el encuadre gótico, sino que además aproximan la percepción del protagonista a la del lector ${ }^{4}$.

3 Énfasis añadido.

4 Todas las citas de este estudio provienen de la primera edición de Aura (México: Ediciones Era, 1962). A continuación se alegarán solo las paginás corespondientes a la cita. Respecto a las sucesivas ediciones llama la atención que se haya prescindido de los dibujos o grabados en color que sintetizan escenas puntuales en cada uno de los capítulos. 
El primer hecho llamativo que observamos se produce en el capítulo de apertura cuando asistimos al enclaustramiento de Felipe Montero, el protagonista, que víctima de un señuelo casi hipnótico se deja atrapar por un anuncio en el periódico: «LEES ESE ANUNCIO: UNA OFERTA DE ESA NATURALEZA no se hace todos los días. Lees y relees el aviso. Parece dirigido a ti, a nadie más. Distraído, dejas que la ceniza del cigarro caiga dentro de la taza de té que has estado bebiendo en ese cafetín sucio y barato. Tú releerás» (9). La primera línea de la edición de 1962, que da comienzo a cada capítulo, se introduce con mayúsculas por lo que en la anterior cita reproducimos la tipografía del original; un elemento ya de entrada visual que llama la atención y la curiosidad del lector. También el verbo que inaugura el discurso en la obra, 'Lees', activa el primero de los sentidos, 'la vista', y que como veremos juega un papel primordial que alumbra y deslumbra al protagonista en momentos clave. Sorprende también el efecto de la poco habitual narración en segunda persona, que aproxima tanto el plano emocional como el lingüístico (Standish, 1991, 438) , «que nos permite ubicar el enunciado en relación con los actantes [...]; [siendo] imposible desligar los registros del habla de las implicaciones en los hechos» (Osuna, 1980, 62), que «convoca a lo dialógico [...] al vínculo del hombre con sus deseos, con la estructura inconsciente de su personalidad» (Mazzei, 1988, 109), y que sirve de instinto a seguir e incluso profetiza sobre el fatídico futuro que el lector presagia e intuye $e^{6}$. Como observamos en el siguiente cuadro, cada capítulo se inicia con una secuencia que se relaciona con un matiz sensorial concreto.

\begin{tabular}{|l|l|l|}
\hline Capítulo & Extracto & Relevancia sensorial \\
\hline I (p. 9) & $\begin{array}{l}\text { LEES ESE ANUNCIO: UNA OFERTA } \\
\text { DE ESA NATURALEZA no se hace todos } \\
\text { los días. Lees y relees el aviso. }\end{array}$ & La vista \\
\hline II (p. 19) & $\begin{array}{l}\text { LA ANCIANA SONREIRÁ, INCLUSO } \\
\text { REIRÁ CON SU TIMBRE agudo y dirá } \\
\text { que le agrada tu buena voluntad [...]. }\end{array}$ & El oído \\
\hline III (p. 28) & $\begin{array}{l}\text { LEES ESA MISMA NOCHE LOS } \\
\text { PAPELES AMARILLOS, escritos con una } \\
\text { tinta color mostaza; a veces, horadados } \\
\text { por el descuido de una ceniza de tabaco, } \\
\text { manchados por moscas. }\end{array}$ & $\begin{array}{l}\text { La vista (con énfasis } \\
\text { en los matices } \\
\text { cobjetos) }\end{array}$ \\
\hline
\end{tabular}

5 Para más información sobre la narración en segunda persona y su relevancia hermenéutica, véase el estudio de Peter Standish sobre los cuentos de Cortázar así como la introducción de la edición de Aura (Durham: University of Durham Modern Language Series, 1986) del mismo autor.

6 En un artículo sobre la técnica compositiva de la novela, »On Reading and Writing Myself: How I Wrote Aura«, Carlos Fuentes nos desvela su interés por el uso de la segunda persona: «You: that word which is mine as it moves, ghostlike, in all the dimensions of space and time, even beyond death». (Tú: esa palabra que es mía mientras se mueve, fantasmal, en todas las dimensiones del espacio y del tiempo, e incluso más allá de la muerte) $(2003,931)$. 


\begin{tabular}{|l|l|l|}
\hline Capítulo & Extracto & Relevancia sensorial \\
\hline IV (p. 40) & $\begin{array}{l}\text { SABES AL CERRAR DE NUEVO EL } \\
\text { FOLIO, QUE POR ESO, vive Aura en } \\
\text { esta casa: para perpetuar la ilusión de } \\
\text { juventud y belleza de la pobre anciana } \\
\text { enloquecida. Arrojas los papeles a un lado } \\
\text { y desciendes [...]. }\end{array}$ & El tacto \\
\hline $\begin{array}{l}\text { DUERMES CANSADO, } \\
\text { INSATISFECHO. YA EN EL SUEÑO } \\
\text { sentiste esa vaga melancolía, esa opresión } \\
\text { en el diafragma, esa tristeza que no se } \\
\text { deja apresar por tu imaginación. Dueño } \\
\text { de la recámara de Aura, duermes en la } \\
\text { soledad, lejos del cuerpo que creerás } \\
\text { haber poseído. [...]. Te llevas las manos a } \\
\text { las sienes tratando de callar tus sentidos } \\
\text { en desarreglo. }\end{array}$ & $\begin{array}{l}\text { Sueño (anulación } \\
\text { de los sentidos); } \\
\text { falacia sensorial } \\
\text { (duda de su propia } \\
\text { percepción de la } \\
\text { realidad) }\end{array}$ \\
\hline
\end{tabular}

Sin embargo, en el capítulo de cierre el protagonista se ve dominado por el sueño donde todos los sentidos dejan de realizar sus funciones vitales, perdiendo así la conciencia de su entorno. Llama la atención el hecho de que incluso durante el sueño, Felipe Montero desconfía una vez más de sus propios sentidos: «Dueño de la recámara de Aura, duermes en la soledad, lejos del cuerpo que creerás haber poseído» (49) 7 . Es precisamente esta duda sobre su realidad ontológica la que le lleva a replantearse la vigencia de su entorno en todo momento, ya que los sentidos le sirven de guía y también le manifiestan múltiples matices que conjuntamente bosquejan el encuadre gótico de la novela.

El paulatino engaño que se desvela conforme avanza la trama no está diseñado por el autor para sorprender al lector al final de la misma, sino más bien como una culminación de un proceso; una apoteósica confirmación o clímax del hecho que se presiente a lo largo de toda la trama y sobre el que, como veremos, se ofrecen indicios cromáticos, que aunque son numerosos y aparecen con frecuencia se pueden delimitar en cuanto a su variedad. Un ejemplo de cómo se utiliza este cromatismo intencionado lo observamos en el predominio del color verde que «facilita el manejo de los últimos episodios» (Taggart, 1983, 220), y que se destila en diferentes tonalidades, como las «largas cortinas verdosas» (11) que Felipe Montero observa desde el mundo exterior antes de entrar en la casona de la calle Donceles, los ojos de Aura, «unos hermosos ojos

7 Énfasis añadido. 
verdes idénticos a todos los hermosos ojos verdes que has conocido o podrás conocer» (18), «el cuero verde» (20) que reviste la mesa de su habitación y claro paralelismo cromático con el tejido que viste a Aura, «tu hermosa Aura vestida de verde» (34), o los «ojos verdes de Consuelo» (38) en su juventud, lo cual se narra a partir de los escritos del General Llorente.

No obstante, la escasa variedad de colores favorece la creación de paralelismos semánticos en diferentes tonalidades como ocurre, por ejemplo, con el color amarillo; como los «papeles amarillentos» (9), los ojos de Consuelo «del color de la córnea amarillenta que los rodea» (16), el «cordón amarillo» (27) que celosamente guarda los pergaminos que despliegan el pasado familiar, «la tinta color mostaza» (28) con la que están escritos, la mirada «amarilla» (33) de Consuelo, que Felipe intenta evadir en más de una ocasión, o «los dientes amarillos» (42) de la vetusta señora que el protagonista recrea inevitablemente durante el sueño. También, el color blanco, «los demás vasos manchados de líquidos blancuzcos» (15), los ojos de la señora Consuelo «cerrados detrás de los párpados colgantes, arrugados, blanquecinos» (36), el «conejo blanco» que la acompaña (37), y que unas líneas después descubrimos que en realidad es una «coneja» (37), o el habitual atuendo de la anciana: «ese traje blanco, ese velo de gasa teñida, rasgada» (52). Como vemos por la disposición de los adjetivos, se trata de una estructura cromática gradual, premonitoria y claramente intencional, que va enlazando diferentes momentos de la narración, y cuyos matices en muchas ocasiones no aparecen como color base o compacto, sino más bien indefinido (amarillento, verdoso, rosado, grisáceo, blancuzco, etc.). Bastan estos ejemplos, por tanto, para discrepar ampliamente de lo que afirma Taggart, quien -refiriéndose al color verdesostiene que «los demás colores no tienen la importancia que tiene lo verde en la obra» $(1983,220)^{8}$.

Como mencionábamos al comienzo de este ensayo, Carlos Fuentes sintetiza cada detalle a la hora de componer el engranaje narrativo $y$, consecuentemente, todos los colores del siguiente cuadro comparativo constatan la relevancia cromática, y por consiguiente semántica, necesaria para plasmar, en palabras de Octavio Paz, «una 'nouvelle' macabra y perfecta a un tiempo - como lo exige el género: la geometría es la antesala del horror» (Paz, 1967, 45). Tal y como apreciamos en el cuadro sinóptico todos los colores en la novela se hallan metódicamente escogidos, dispuestos y predispuestos.

8 A pesar de no mostrar un especial interés por la relevancia cromática presente en la obra, Taggart se fija en que «los colores de las cintas o cordones que se usan para amarrar los documentos del difunto general. El primero es un cordón amarillo; el segundo, una cinta azul, y el tercero, una cinta roja. Este recurso sirve para simbolizar y aumentar la intensidad e importancia de lo que se va a revelar en los respectivos folios» $(1983,220)$. 


\begin{tabular}{|c|c|c|}
\hline Color en orden de aparición & Función y Contexto & Capítulo \\
\hline \multirow{5}{*}{ Amarillo } & $\begin{array}{l}\text { papeles amarillentos (p. 9) } \\
\text { córnea amarillenta (p. 16) }\end{array}$ & I \\
\hline & $\begin{array}{l}\text { metal dorado (p. 20) } \\
\text { muros oro (p. 20) } \\
\text { cordón amarillo (p. 27) }\end{array}$ & II \\
\hline & $\begin{array}{l}\text { papeles amarillos (p. 28) } \\
\text { tinta color mostaza (p. 28) } \\
\text { mirada amarilla (p. 33) } \\
\text { papeles amarillos (p. 34) }\end{array}$ & III \\
\hline & dientes amarillos (p. 42) & IV \\
\hline & $\begin{array}{l}\text { traje de novia amarillento (p. } 53 \text { ) } \\
\text { hojas amarillas (p. } 54)\end{array}$ & $\mathrm{V}$ \\
\hline \multirow{4}{*}{ Negro } & $\begin{array}{l}\text { zapatos negros (p. 10) } \\
\text { punto negro (p. 16) } \\
\text { ojos negros (p. 20) }\end{array}$ & I \\
\hline & $\begin{array}{l}\text { zapatos negros (p. 29) } \\
\text { la campana pintada de negro (p. 30) } \\
\text { Cristo negro (p. 34) }\end{array}$ & III \\
\hline & $\begin{array}{l}\text { fondo negro (p. 42) } \\
\text { pelo negro (p. } 45) \\
\text { madera negra (p. 46) } \\
\text { Cristo negro (p. 47) } \\
\text { peluca negra (p. 47) } \\
\text { rodillas negras (p. 48) }\end{array}$ & IV \\
\hline & $\begin{array}{l}\text { café negro (p. 53) } \\
\text { pelo negro (p. 56) } \\
\text { pelo negro (p. 56) } \\
\text { nubes negras (p. 57) }\end{array}$ & $\mathrm{V}$ \\
\hline
\end{tabular}




\begin{tabular}{|c|c|c|}
\hline Color en orden de aparición & Función y Contexto & Capítulo \\
\hline \multirow{5}{*}{ Verde } & $\begin{array}{l}\text { cortinas verdosas (p. 11) } \\
\text { calma verde (p. 18) } \\
\text { ojos verdes (p. 18) }\end{array}$ & I \\
\hline & $\begin{array}{l}\text { muros oliva (p. 20) } \\
\text { cuero verde (p. 20) } \\
\text { terciopelo verde (p. 22) } \\
\text { Aura viste de verde (p. 22) } \\
\text { limo verdoso (p. 22) } \\
\text { ojos verdes (p. 24) }\end{array}$ & II \\
\hline & $\begin{array}{l}\text { Aura vestida de verde (p. 34) } \\
\text { yeux verts (p. 38) } \\
\text { los ojos verdes de Consuelo (p. 38) } \\
\text { yeux verts (p. 38) } \\
\text { verts (p. 39) } \\
\text { verts (p. 39) } \\
\text { vestida de verde (p. 39) }\end{array}$ & III \\
\hline & $\begin{array}{l}\text { tafeta verde (p. 42) } \\
\text { Aura vestida de verde (p. 45) } \\
\text { ojos verdes (p. 45) }\end{array}$ & IV \\
\hline & $\begin{array}{l}\text { tafeta verde (p. 50) } \\
\text { velo verdoso (p. 50) } \\
\text { ojos verdes (p. 54) } \\
\text { ojos verdes (p. 56) } \\
\text { bata verde (p. } 58 \text { ) }\end{array}$ & V \\
\hline Gris & luz grisácea (p. 12) & I \\
\hline \multirow{4}{*}{ Rojo } & $\begin{array}{l}\text { ojos rojos (p. 13) } \\
\text { seda roja (p. 14) }\end{array}$ & I \\
\hline & $\begin{array}{l}\text { terciopelo rojo (p. 20) } \\
\text { líquido rojo (p. } 22)\end{array}$ & II \\
\hline & $\begin{array}{l}\text { tierra rojiza (p. } 44) \\
\text { el rojo de los labios (p. 45) } \\
\text { seda escarlata (p. } 47)\end{array}$ & IV \\
\hline & cinta roja (p. 54) & $\mathrm{V}$ \\
\hline
\end{tabular}




\begin{tabular}{|c|c|c|}
\hline Color en orden de aparición & Función y Contexto & Capítulo \\
\hline \multirow{4}{*}{ Blanco } & $\begin{array}{l}\text { un pelo muy blanco (p. 14) } \\
\text { cuello blanco (p. 14) } \\
\text { líquidos blancuzcos (p. 15) }\end{array}$ & I \\
\hline & $\begin{array}{l}\text { párpados blanquecinos (p. 36) } \\
\text { conejo blanco (p. 37) }\end{array}$ & III \\
\hline & $\begin{array}{l}\text { flores blanquecinas (p. 44) } \\
\text { muslos color de luna (p. 45) } \\
\text { pelo blanco (p. 47) } \\
\text { sábanas blancas (p. 48) }\end{array}$ & IV \\
\hline & $\begin{array}{l}\text { traje blanco (p. 50) } \\
\text { tinta blanca (p. 56) } \\
\text { barba blanca (p. 56) } \\
\text { pelo blanco de Aura (p. 59) } \\
\text { pelo plateado (p. 60) }\end{array}$ & V \\
\hline \multirow[b]{2}{*}{ Azul } & aguamanil azul (p. 20) & II \\
\hline & $\begin{array}{l}\text { cinta azul (p. 36) } \\
\text { túnica azul (p. 38) }\end{array}$ & III \\
\hline Rosa & ojos rosados (p. 21) & II \\
\hline
\end{tabular}

De este pormenorizado análisis se desprende asimismo que de todos los colores tan sólo el amarillo, que metonímicamente identifica a la cadavérica señora Consuelo, y el verde, que caracteriza a la taciturna Aura, se mantienen a lo largo de los cinco capítulos de los que consta la obra. Con esta técnica compositiva, Carlos Fuentes logra incidir directamente sobre la memoria cromática del lector y sobre el cúmulo de sensaciones visuales que se consiguen mediante la inserción deliberada de estos epítetos, que el protagonista se resiste a contrastar y mucho menos a aceptar, debido al efecto hipnótico que Aura ejerce sobre él, y que no obstante el lector va coleccionando como indicios que rezuman el desenlace de la novela.

Prueba de la clara vinculación entre la señora Consuelo y su sobrina Aura la encontramos ya de manera premonitoria en el primer capítulo: «la joven inclinará la cabeza y la anciana, al mismo tiempo que ella, remedará el gesto» (17). Al final del capítulo IV se confirma la ambivalencia entre Aura y Consuelo que transporta al lector a observar una sincronizada mímesis entre ambas: «la señora Consuelo que te sonríe, cabeceando, que te sonríe junto con Aura que mueve la cabeza al mismo tiempo que 
la vieja: las dos te sonríen, te agradecen. Recostado, sin voluntad, piensas que la vieja ha estado todo el tiempo en la recámara» (48). Y finalmente en el último capítulo se ratifica la premonición que alumbraba desde las primeras páginas: «Y cuando te estés secando, recordarás a la vieja y a la joven que te sonrieron, abrazadas, antes de salir juntas, abrazadas: te repites que siempre, cuando están juntas, hacen exactamente lo mismo: se abrazan, sonríen, comen, hablan, entran, salen, al mismo tiempo, como si una imitara a la otra, como si de la voluntad de la una dependiese la existencia de la otra» $(50)$.

Existen dos momentos clave en la narración que encadenan una sucesión de eventos sensoriales. Todos los sentidos aparecen en el transcurso de la trama de manera aislada, pero también en relación con escenas concretas en las que se ve necesario apelar a los sentidos $y$, por consiguiente, aludir a una referencia sensorial concreta de manera implícita o explícita. Por ejemplo, la vista es el sentido que se ve anulado en su función vital principalmente por la ausencia de luz, «Desciendes contando los peldaños: otra costumbre inmediata que te habrá impuesto la casa de la señora» (21), aunque en ocasiones también el protagonista se ve deslumbrado por cambios repentinos en su perceptibilidad, «Te moverás unos pasos para que la luz de las velas no te ciegue» (18), o «sonríes al darte cuenta de que ha bastado la luz del crepúsculo para cegarte y contrastar con la penumbra del resto de la casa» (20); el olfato aparece cuando el protagonista se adentra en el jardín que cuida Aura, o cuando respira el ambiente de humedad; el oído le guía cuando hay ausencia de luz, siguiendo el ruido de la bata de tafeta de Aura, de los espectrales gatos, o de la recurrente campanilla que Aura repica para llamar a la mesa y que marca el transcurrir del día, «te das cuenta de que no la sigues con la vista, sino con el oído; sigues el susurro de la falda» (19); el gusto, con el repetitivo menú de riñones en salsa y el espeso vino; el tacto, con sensaciones que tienen que ver con el frío, la humedad y como consecuencia de la ausencia de luz presente en todo momento en la casa, «Empujas la puerta [...] te obligarás a conocerla y reconocerla por el tacto. Avanzarás como un ciego con los brazos extendidos rozando la pared» (21), y que también: «nos remite a una repulsión al contacto mutuo entre los personajes, pese a las ansias del protagonista por depositar sus manos sobre Aura» (Muñoz-Basols, 2003, 81) ${ }^{9}$.

En los contactos directos entre Felipe Montero y Aura-Consuelo asistimos a dos momentos particularmente relevantes en los que los cinco sentidos se suceden y se superponen para conseguir un efecto conjunto. Este hecho se produce sobre todo donde no hay más que un espacio reducido, el de la cama, y los sentidos cumplen

9 En varias ocasiones nos narra cómo está a punto de tocarla, «pero ella aparta el contacto de tus manos» (23), que como advierte Javier Muñoz-Basols, dicho momento se convierte «en una amalgama de sensaciones que lleva a Felipe a corroborar el correcto funcionamiento de su sistema sensorial» (Muñoz-Basols, 2003, 81). 
la función de informarnos sobre la realidad ontológica del momento, ya sean los contactos reales o intuidos a través del ambiguo sueño del protagonista, como sucede en el capítulo III:

Y cuando el rostro de ojos vaciados se acerca al tuyo, despiertas con un grito mudo, sudando, y sientes esas manos que acarician tu rostro y tu pelo, esos labios que murmuran con la voz más baja [...]. Alargas tus propias manos para encontrar el otro cuerpo, desnudo, que entonces agitará levemente el llavín que tú reconoces, y con él a la mujer que se recuesta encima de ti [...] pero hueles en su pelo el perfume de las plantas del patio, sientes en sus brazos la piel más suave y ansiosa, tocas en sus senos la flor entrelazada de las venas sensibles, vuelves a besarla y no le pides palabras $(35-36)^{10}$.

Por lo tanto, la vista (el acercamiento de ambos rostros), el oído (del murmullo de sus palabras), el olfato (del olor característico de Aura), el tacto (del contacto de los dos cuerpos), y el gusto (de sus besos) se unen con un mismo fin, el de transmitir el mayor número de sensaciones. No resulta una coincidencia que este hecho se vuelva a repetir en el capítulo IV, cuando se produce otra vez un contacto carnal entre Aura y Felipe, aunque esta vez sin el desconcierto onírico de la escena anterior, y que reafirma además el inevitable paso del tiempo y el parecido cada vez más explícito y perceptible de Aura con su tía, la señora Consuelo:

Aura vestida de verde, con esa bata de tafeta por donde asoman, al avanzar hacia a ti la mujer, los muslos de color de luna: la mujer, repetirás al tenerla cerca, la mujer, no la muchacha de ayer, -cuando toques sus dedos, su talleno podía tener más de veinte años; la mujer de hoy -y acaricies su pelo negro, suelto, su mejilla pálida-parece de cuarenta: algo se ha endurecido entre ayer y hoy, alrededor de los ojos verdes; el rojo de los labios se ha oscurecido fuera de su forma antigua, como si quisiera fijarse en una mueca alegre, en una sonrisa turbia: como si alternara, a semejanza de esa planta del patio, el sabor de la miel y de la amargura $(45)^{11}$.

Como hemos visto, los sentidos corroboran en todo momento el espacio que rodea al protagonista y el vínculo con su alter ego: el lector. Sin embargo, esta proliferación de matices sensoriales permite que el lector desarrolle a lo largo de la obra un 'sexto sentido'; el sentido de la intuición, el de las numerosas premoniciones, paralelismos cromáticos y semánticos que hemos reconstruido aquí a partir de los cinco sentidos y que, sin embargo, el protagonista no es capaz de percibir, activar o discernir: «Desconoce los símbolos que se le presentan para informarle y, por lo tanto, deambula sin

10 Énfasis añadido.

11 Énfasis añadido. 
sentido en busca de una identidad que nunca ha de encontrar dado a su propia ignorancia» (Magráns, 1998, 62).

Queda demostrado, por lo tanto, el grado de dependencia del género gótico de la percepción sensorial, y por extensión, de todos aquellos elementos descriptivos, estilísticos y retóricos que en Aura contribuyen a este propósito. La novela, desde la fuerza ilocutiva de su transparente, intangible y lacónico título, «le va dando al lector las armas para su autoconocimiento, y autorreflexión [...] y [le] otorga [...] la posibilidad de descubrir y reflexionar en un diálogo intersubjetivo entre lo simbólico y lo imaginario» (Collette, 1995, 295). He aquí que podamos concluir que tanto el cromatismo como la percepción sensorial posibilitan en Aura la configuración del marco semántico y sirven de epítome de toda la gama de sensaciones góticas que se encuentran a disposición del lector.

\section{Bibliografía}

Bell, M., The Fuentes of Fuentes and the Aura of Aura: Carlos Fuentes' Up Dating of a Cervantean Theme, Inti: Revista de Literatura Hispánica 45, 1997, pp. 105-114.

Collette, M., La fase del espejo, lo simbólico y lo imaginario en la novela Aura, de Carlos Fuentes, Revista Canadiense de Estudios Hispánicos 19 (2), 1995, pp. 281298.

De Man, P., The Epistemology of Metaphor, Critical Inquiry 5 (1), 1978, pp. 13-30.

Estébanez Calderón, D., Diccionario de términos literarios, Madrid 2001.

Fontanier, P., Les figures du discours, Paŕis [1827] 1968.

Fuentes, C., Aura, México 1962.

Fuentes, C., Aura, Peter Standish (ed.), Durham 1986. Fuentes, C., On Reading and Writing Myself: How I Wrote Aura, en: Twayne Companion to Contemporary World Literature: From the Editors of World Literature Today (ed. Genova, P. A.), New York 2003, pp. 923-931.

Magráns, R., La llamada de la madriguera: Aura, en: La obra de Carlos Fuentes: una visión múltiple (ed. Hernández de López, A.), Madrid 1998, pp. 53-62.

Mazzei, N., La novela latinoamericana: estudios críticos, Buenos Aires 1988.

Muñoz-Basols, J., La recreación del género gótico a través de la percepción sensorial: la construcción de la hipotiposis en Aura de Carlos Fuentes, Atenea 23 (2), 2003, pp. 73-85.

Osuna, Y., Tres ensayos de análisis literario, Mérida 1980.

Paz, O., Corriente alterna, México 1967. 
Ravelo, R., Prohibido leer a Gabo y a Fuentes, La jornada, lunes 16 de abril de 2001, http://www.jornada.unam.mx/2001/04/16/040n1con.html [1.3. 2007].

Saludes, E., Correspondencia entre tema y estilo en Aura, en: La obra de Carlos Fuentes: una visión múltiple (ed. Hernández de López, A.), Madrid 1988, pp. 87-94.

Standish, P., La segunda persona y el narratario en los cuentos de Cortázar, Modern Language Notes 106 (2), 1991, pp. 432-440.

Taggart, K., Yáñez, Rulfo y Fuentes: el tema de la muerte en tres novelas mexicanas, Madrid 1983. 
Javier Muñoz-Basols

\section{Kromatičnost in percepcija čutov: nova spoznanja - zgradbi romana Aura Carlosa Fuentesa}

Ključne besede: kromatičnost, opisovanje, stilistika, hipotipoza, gotska (oziroma grozljiva) književnost, mehiška književnost, percepcija čutov

Ena glavnih zahtev gotskega žanra je izguba občutka za stvarnost. To značilnost, ki $\mathrm{v}$ veliko primerih vodi v strah ali celo grozo, je mogoče doseči predvsem $\mathrm{z}$ zatekanjem k čutom. V romanu Aura Carlosa Fuentesa opisovanje preseže meje percepcije čutov, saj bralec ni zgolj voden, ampak se, kot bi bil zapeljan, pusti voditi, očaran s čutno razvejanostjo, ki veje iz zapleta.

$\mathrm{V}$ študiji bomo pokazali, kako kromatičnost in čutna zaznavnost potencirata splošen smisel romana, hkrati pa razkrivata številne slogovne značilnosti, ki potrjujejo hermenevtično relevantnost opisanega. Izhajajoč iz podrobne študije uporabe jezika, bomo analizirali tvorjenje pripovedi s tehniko kromatične progresije, ki uspešno združuje percepcijo čutov in psihologijo glavnega junaka ter strne celo vrsto bralcu razpoložljivih gotskih občutkov. 